\title{
Panel Discussion: Transparency in the Practice of Monetary Policy
}

\section{The Value of Transparency in Conducting Monetary Policy}

\author{
Charles Freedman
}

$\mathrm{n}$ this paper, I discuss transparency in the conduct of monetary policy from three perspectives. First, I look at why central banks have chosen to become more transparent in recent years. I then set out the measures taken by the Bank of Canada to increase transparency. The third section of the paper examines a number of issues that could be grouped under the heading "Are there limits to what should be made public?"

\section{WHY HAVE CENTRAL BANKS BECOME INCREASINGLY TRANSPARENT?}

There are two key factors behind the move to increased transparency on the part of central banks. The first is the relationship between transparency and the effectiveness of monetary policy. The second is the link between transparency and accountability. Let me examine each of these motivations in turn.

The way in which monetary policy is conducted by central banks has changed significantly in recent years. Not too long ago, central banks said relatively little about their monetary policy and allowed their actions to speak for themselves. Today, in contrast, central banks are very explicit in setting out the objectives of policy, the way in which they view the operation of the transmission mechanism between their policy actions and their goal variables, their outlook for economic activity and inflation, and their setting of the policy interest rate. It is now generally believed in the central banking community that this increased transparency improves the functioning of monetary policy in a number of dimensions.

The first dimension involves the understanding

Charles Freedman is a deputy governor at the Bank of Canada. The author thanks Paul Jenkins and David Longworth for comments on earlier drafts. The views expressed here are those of the author and should not be attributed to the Bank of Canada.

(C) 2002, The Federal Reserve Bank of St. Louis. of the general public, both directly and through the media. Like all public policies, monetary policy benefits from increased public support and understanding. In particular, monetary policy, which at times involves the need to take tightening actions to prevent the economy from overheating, would find itself the subject of considerable public criticism if the public did not understand the reason for its actions. The key point in developing such an understanding is to make clear what monetary policy can do, as well as what it cannot do. Thus, central banks should emphasize that the role of monetary policy is to control inflation in the medium-to-long run ${ }^{1}$ and that an environment of low inflation will help the economy to achieve a higher level or rate of growth of productivity. Moreover, a monetary policy aimed at inflation control will tend to moderate the economic cycle, although it cannot eliminate it. In focusing on these benefits, the central bank should make clear that the objective of low inflation, or price stability, is a means to an end, the end being a well-functioning economy, and not an end in itself. Examples from postwar economic history that focus on the poor performance of the economy at times of high inflation and its better performance at times of low inflation can be very helpful in this regard.

In addition to generating broad public support for the goal of low inflation, transparency (along with the credibility of policy) can contribute to behavior that will facilitate the achievement of the goal. Thus, wage and price setting that is done in the context of an environment of confidently held expectations of low and stable inflation will make the task of the central bank easier.

The second dimension of the relationship between transparency and the functioning of monetary policy involves the behavior of participants in financial markets. When financial markets understand and anticipate the actions of the central bank, the first steps in the transmission mechanism between policy actions and economic activity and inflation work more smoothly.

\footnotetext{
1 This could be done in the context of an explicit inflation target (as in Canada) or a more general commitment to low inflation (as in the United States).
} 
For example, when the central bank and market participants have a similar interpretation of factors affecting the economic outlook, data releases will tend to lead to movements in market interest rates (and the exchange rate) in advance of, and consistent with, the policy actions that are subsequently taken by the central bank. Thus, new data indicating increased pressures on capacity and, hence, an increased likelihood of higher future inflation will result in higher interest rates across much of the yield curve, while signs of weakness in the economy and an increased likelihood of lower future inflation will result in lower interest rates.

I would emphasize at this point that central banks should not and do not simply follow the market. If views differ between the central bank and the market as to the likely outlook and the appropriate policy, the central bank must follow its own best judgment and explain to the market the reasons for its actions. But the enhanced transparency and improved communications of recent years reduce the likelihood of sharply different views as to appropriate policy, although they do not entirely eliminate it. In short, if market expectations are broadly in line with the direction of policy, there is likely to be less volatility in financial markets and smoother incorporation of policy actions into interest rates and exchange rates.

Communications play an important role in the transmission of the views of the central bank to the public and to markets. Hence, a great deal of attention is now paid to the way that central banks present their key messages (see Blinder et al., 2001, and Jenkins, 2001). Improving the effectiveness of monetary policy through greater transparency requires proactive and well-planned communications.

The second key factor motivating the trend to greater transparency is the tendency toward greater accountability, an important element in the framework supporting the independence of central banks. On this, I can be brief. Increasingly around the world, central banks are being given responsibility for carrying out monetary policy in the context of objectives that are defined in legislation or treaty and/or agreed upon by the government and central bank. As nonelected bodies, central banks are typically held accountable to government or parliament or the general public for their stewardship of policy. In order for this accountability to be effective, the oversight body must have sufficient information to evaluate the conduct of policy by the central bank. Such information is provided by central banks in the context of their overall communications strategy, and the need to provide this information has played an important role in the increased transparency of monetary policy.

\section{HOW HAS THE BANK OF CANADA BECOME MORE TRANSPARENT?}

While I now turn to the ways in which the Bank of Canada has become more transparent in recent years, I would note that similar (although not identical) changes have been put in place in most central banks. Changes in the direction of increased transparency can be grouped under a number of headings - the goal of policy, the transmission mechanism, the outlook, the policy instrument, and the means by which the Bank communicates information.

\section{Goal of Policy}

In February 1991, the Bank of Canada and the government of Canada publicly announced their jointly agreed inflation-control targets. The initial targets aimed at a gradual reduction of the target rate of inflation from 3 percent at the end of 1992 to 2 percent at the end of 1995 . Since then the targets have been renewed three times, each time with a target range centered on 2 percent. The most recent agreement, announced earlier this year, extended the 2 percent target to the end of 2006. The move to a five-year term for the agreement (from the three-year term in previous agreements) is aimed at enhancing the longer-term predictability of the rate of inflation.

The range for the target has been plus or minus 1 percent throughout. The Bank has also been very explicit that the horizon for bringing inflation back to the target midpoint if it moves away from that level would be six to eight quarters. While the target has been defined in terms of the 12-month rate of increase of the total consumer price index (CPI), the Bank has used a publicly announced measure of core inflation as a policy guide in assessing future inflation developments.

\section{Transmission Mechanism}

The Bank of Canada has explained in some detail the way in which it views the transmission mechanism from its policy actions to market interest rates and the exchange rate, and then to output and inflation (see Thiessen, 1995). It has also published a number of articles on the large macroeconomic 
model, the quarterly projection model, or QPM (Poloz, Rose, and Tetlow, 1994), that currently provides the basis (combined with staff judgment) for the principal staff projection. An alternative view of the transmission mechanism focuses on the way that developments in the monetary aggregates directly affect the spending behavior of households and businesses. (See Engert and Selody, 1998, and Laidler, 1999, for expositions of this approach.) The various multi-equation and single-equation models linking monetary aggregates to economic activity have also been made public. And the Bank has explained how the staff projection, the monetarybased forecasts, and the information gathered by the Bank's regional offices (through formal surveys and anecdotally) are integrated in the course of making monetary policy decisions (see Longworth and Freedman, forthcoming).

\section{Economic and Inflation Outlook}

Central banks differ in the degree of detail that they publish on their economic and inflation outlook. And they also differ in the interest rate and exchange rate conventions that underlie their projections.

The Bank of Canada presents a detailed discussion of recent economic and inflation developments as well as its outlook for the future once per quarter either in its monetary policy report (in April and October) or in its update (in January and July). The outlook typically focuses on expected developments over the next 6 to 18 months in gross domestic product (GDP), the output gap, total CPI, and core CPI. A qualitative assessment is given of the risks surrounding the outlook, but there is no attempt to quantify the risks.

Speeches by the Governor and other members of the Governing Council of the Bank are used to sketch out changes in the outlook between publications. As well, a press release is issued on each of the eight preannounced fixed action dates, whether or not the policy interest rate is changed, and this gives the Bank a further opportunity to give some sense of its views of likely future developments in the economy and inflation.

\section{Policy Interest Rate}

Until a few years ago, markets had to infer a central bank's target for the policy interest rate from its actions, and it was not always immediately clear from these actions whether or not the policy rate target had changed. Now, the target for the policy rate is announced explicitly, normally on preannounced dates, almost everywhere.

In Canada, there were a number of changes that made the setting of the policy interest rate increasingly transparent. In 1994, the Bank established an operational target band of 50 basis points for the overnight interest rate. Market participants recognized a change in the rate when the Bank informed them of its intention to intervene at the new limits of the band (using repos or reverse repos to enforce those limits). In early 1996, the Bank began to issue a press release whenever there was a change in the band, giving an explanation for the change. Shortly thereafter, the Bank Rate (the rate charged by the Bank on advances to participants in the payments system) was set at the top of the band. ${ }^{2}$ In 1999, the target rate was explicitly set as the midpoint of the band. With the movement to fixed announcement dates in late 2000 , a press release was issued on each date regardless of whether or not there was a change in the policy rate.

\section{Communications}

The Bank now aims at an integrated communications strategy in order to disseminate its key messages to the various target audiences throughout the year. As noted earlier, each year this involves two monetary policy reports, two updates to the report, eight press releases on the fixed announcement dates, and speeches by the Governor and other members of the Governing Council (in many cases as part of a regional outreach program). In addition, there are background briefings, press conferences with the Governor following the release of the report and the update, and testimony by the Governor before the House of Commons Finance Committee following the publication of each report.

In recent years, the Bank has instituted a media "lock-up" arrangement in which the media can read key Bank reports and write their stories prior to the official publication time, for release at that time. As well, there are regular media briefings during the lock-up, where officials can deal with technical questions and clarify other issues (on an unattributed basis) for the media that are present. The result has been a clear improvement in the quality of the reporting compared with the period when the media received the reports at the official

\footnotetext{
2 It had previously been set equal to the average rate on Treasury bills
} at the weekly auction plus 25 basis points. 
release time and the wire services competed to get out the first headline.

The establishment of the fixed announcement dates has also had a beneficial effect on the discussion surrounding Canadian monetary policy by both journalists and market commentators. Whereas previously there had been a tendency for the discussion to center on whether or not the Bank would follow the Fed's movements, the focus has shifted to what is appropriate for the Canadian economy in its current and prospective economic circumstances. ${ }^{3}$

\section{ARE THERE LIMITS TO WHAT SHOULD BE MADE PUBLIC?}

On the surface, this seems like an odd question. Can there ever be too much of a good thing? But as one reflects on the nature of transparency and communications, it becomes clear that certain steps in the direction of increased transparency could actually be counterproductive. Let me begin with an admittedly extreme example, turn to the principle at issue, and then return to some examples.

Should the policymaking body's deliberations before its decisions be televised or Web-cast? Even strong proponents of transparency come to the conclusion that such an initiative could be harmful for a number of reasons. First, policymakers could be inhibited from taking different points of view in the course of the discussion (i.e., playing devil's advocate). Second, it would make it more difficult for them to change their minds on the appropriate decision for the policy interest rate as the debate progressed and as different perspectives on the issue were discussed, since they would appear to be "waffling" on the decision. Third, making the deliberations public would likely lead to participants making more formal presentations (with perhaps a more entrenched initial position), replacing the more informal discussion in which the dynamic of the debate plays an important role in arriving at a decision. ${ }^{4}$ In short, the view that opening the deliberations to the public could well lead to a deterioration in the quality of the decisionmaking process has acted to prevent such a development even in those central banks that are the most enthusiastic supporters of transparency. (See Blinder et al., 2001, for a detailed discussion of this issue.)

Let me now examine the question of the limits of transparency from a broader perspective, drawing on an interesting and insightful paper by Bernhard Winkler (2000) of the European Central Bank (ECB). Winkler argues (p. 18) that "in a world where- unlike in most standard economic models-cognitive limits matter, more information and greater detail does not by itself translate into greater transparency and better understanding, nor does it necessarily lead to more efficient decision-making." Winkler notes that there are several aspects of transparency, which may possibly conflict with each other. These include (i) openness, or the amount and precision of information provided; (ii) clarity in the presentation and interpretation of information; (iii) common understanding by the sender and receiver of information; and (iv) honesty, or the correspondence of the internal framework of analysis with the presentation used for external communication.

As an example of potential conflict, we can compare openness and clarity. Central bank projections typically produce time paths for dozens or even hundreds of economic variables. Yet most central banks communicate to the public their quantitative outlook only for the broadest economic measures, such as output and inflation. ${ }^{5}$ This reflects the view that increased openness, in the sense of presenting enormous amounts of detail, would reduce the clarity of the central bank's message about future developments rather than increase it.

In passing, I would note that one issue that all central banks are struggling with is how to characterize and communicate the risks around their baseline case forecast. Some, such as the Bank of England and the Riksbank, present a form of probability distribution that is intended to indicate the variance around the central forecast. Others, such as the Federal Reserve and the Bank of Canada, are more qualitative in their presentation of the balance of risks. But I do not think that any central bank has been completely successful thus far in communicating the nature of the risks surrounding its outlook for the economy and inflation.

The notion of "honesty" in the correspondence of the internal framework of analysis and external communications also gives rise to some interesting

\footnotetext{
3 See Bank of Canada (2000) for a discussion of the benefits anticipated from the movement to fixed announcement dates.

4 Presentations at FOMC meetings by Board members and Reserve Bank presidents appear to have become somewhat more formal since 1993. In the fall of that year, the FOMC was made aware that the transcripts of the tape recordings of the meetings since March 1976 had been retained. The FOMC subsequently decided that lightly edited verbatim transcripts of the meetings would be released with a five-year delay.

5 There is often considerable qualitative discussion of some of the components of these broad measures, but most central banks do not give precise estimates of their projections of these components.
} 
issues. Economists, whether in universities or markets, would like central banks to be more explicit in setting out their reaction function to various contingencies. But central banks, while they spend a lot of time considering the appropriate response to various shocks, do not have an explicit, quantitative pre-agreed reaction function for every type of shock. To quote John Vickers (1998, pp. 370-71):

In situations of any complexity, there is a tension between a complete contract (i.e. one that specifies what is to happen in every eventuality) and having a good contract (i.e. one that entails good decisions in every eventuality). If the same is true for policy reaction functions, then residual discretion is sensible and so residual uncertainty is inevitable.

One reason that it is not possible to develop a simple reaction function is that there is no model of the economy that is universally accepted. ${ }^{6} \mathrm{With}$ model uncertainty, there cannot be a simple reaction function, especially when different weights are attached to the projections from the various models in different circumstances. In this context I would note that one of the perceived advantages of the Taylor rule is that it is robust across models. But while the Taylor rule can be useful as an indicator of policy in many circumstances, it is not a reaction function that sets out a monetary policy response to all contingencies. A second reason that there cannot be a simple reaction function is that the information used in coming to a decision involves more variables than can be incorporated in any such function. For example, in the early 1990s, the reluctance of commercial banks to extend loans (Chairman Greenspan's "headwinds") played an important role in the Fed's conduct of policy. More recently, the increased rate of growth of productivity operated through a number of channels to affect economic behavior and thereby to influence the Fed's decisionmaking. And, currently, the confidence of firms and households in light of the terrorist attacks of September 11 is playing an important role. While a simple relationship such as a Taylor rule can be a helpful guide to policymaking, it cannot incorporate all the factors that feed into the decisionmaking process (especially in an open economy).

\section{CONCLUDING REMARKS}

Central banks have come a long way in recent years in the direction of increased transparency.
And this has been very helpful in improving the effectiveness of monetary policy and enhancing the accountability of the central bank.

But there continue to be interesting challenges as to future directions in which central banks should go. How much detail should be included in the outlook? Whose forecast is being released-that of the staff (as in the case of the ECB) or that of the policymaking body (as in the case of the Bank of England)? What convention, if any, should be used for the interest rate path on which the outlook is based? ${ }^{7}$ How does the central bank communicate most effectively that its outlook is conditional on current information and that the outlook will change as new information is received? How can it best communicate the risks and uncertainties surrounding its outlook?

In my view, the central bank's approach to answering each of these questions should be based on an analysis of what would be most effective in enhancing the understanding of the public, the markets, and the media. This may be different in different countries. And it may change over time as the sophistication of the targeted audiences changes.

\section{REFERENCES}

Bank of Canada. "Bank of Canada to Adopt Fixed Dates for Announcing Bank Rate Changes." Ottawa, 19 September 2000.

Bank of England. Economic Models at the Bank of England. London: Bank of England, 1999.

Blinder, Alan; Goodhart, Charles; Hildebrand, Philipp; Lipton, David and Wyplosz, Charles. How Do Central Banks Talk? Geneva Report on the World Economy No. 3. London: Centre for Economic Policy Research, October 2001 .

Engert, Walter and Selody, Jack. "Uncertainty and Multiple Paradigms of the Transmission Mechanism." Working Paper 98-7, Bank of Canada, Ottawa, 1998.

Jenkins, Paul. "Communicating Canadian Monetary Policy: Towards Greater Transparency." Remarks to the Ottawa Economics Association, Ottawa, Canada, 22 May 2001.

\footnotetext{
6 See, for example, Bank of England (1999) for the various models that the Bank uses in its policy formulation.

7 See Kohn (2000) and Svensson (2001).
} 
Kohn, Donald L. "The Kohn Report on MPC Procedures." Bank of England Quarterly Bulletin, Spring 2001, pp. 35-49.

Laidler, David. "The Quantity of Money and Monetary Policy." Working Paper 99-5, Bank of Canada, Ottawa, 1999.

Longworth, David and Freedman, Charles. "Models, Projections and the Conduct of Policy at the Bank of Canada." Prepared for the conference Stabilization and Monetary Policy: The International Experience, Bank of Mexico, 14-15 November 2000 (forthcoming).

Poloz, Stephen; Rose, David and Tetlow, Robert. "The Bank of Canada's New Quarterly Projection Model (QPM): An Introduction." Bank of Canada Review, Autumn 1994, pp. 23-38.
Svensson, Lars E.O. "Independent Review of the Operation of Monetary Policy in New Zealand: Executive Summary of the Report to the Minister of Finance.” Reserve Bank of New Zealand Bulletin, March 2001, pp. 4-11.

Thiessen, Gordon G. "Uncertainty and the Transmission of Monetary Policy in Canada." Bank of Canada Review, Summer 1995, pp. 41-58.

Vickers, John. "Inflation Targeting in Practice: The UK Experience." Bank of England Quarterly Bulletin, November 1998 , pp. 368-75.

Winkler, Bernhard. "Which Kind of Transparency? On the Need for Clarity in Monetary Policy-Making." Working Paper No. 26, European Central Bank, 2000.

\section{The Value of Transparency in Conducting Monetary Policy: The Czech Experience}

\section{Václav Klaus}

My remarks reflect more my political experience during the last decade, after the fall of communism in my country and elsewhere, than any well-defined theoretical position.

As I see it, transparency does not represent the main and most important issue of monetary policy. Transparency itself is undoubtedly a positive feature, but to concentrate on transparency without taking into consideration other things means missing, if not hiding, something that is more relevant.

In my understanding, the more relevant issues or the prior issues are the quality of the monetary regime and the way in which monetary policy reflects the preferences of society. An error in either of them is very costly.

Let me start with the second issue, with the problem of the independence of the central bank. I must admit I have a problem with it-as someone who, as minister of finance, introduced it into my country. I can probably afford to make such a "politically incorrect" statement here because I have

Václav Klaus, former finance minister and prime minister, is the president of the Chamber of Deputies of the Parliament of the Czech Republic. some justification for it. In the communist era, we were-among other things - dreaming about rational monetary policy and we considered the independence of a central bank to be a necessary precondition for it. Now, after 12 years of its absolute independence in my country, I see this issue in a more complicated way. I see it as a principal-agent problem. There are many arguments that the central bank should be just an agency that operates to meet policy objectives set by society or its legal representatives. In accordance with this view, the independence of a central bank should be limited to the independence in choosing instruments, not policy objectives. This is not, however, the case in my country. Transparency is, therefore, not the main issue.

Looking at the title of this discussion, we are supposed to speak not about monetary regimes but about monetary policy. Nevertheless, it seems to me that there is a difference in transparency between the regime of discretionary monetary policy and the regime of policy of rules. Discretionary policy cannot be-perhaps even should not be - transparent (as I understand transparency).

My personal experience with pegged exchange rate policy, which was considered to be the most suitable policy for transition economies 10 years ago, is not a good one. I was very much afraid of accepting it at the end of 1990, but at that time the International Monetary Fund did not listen to any arguments in this respect. This policy, however, in the first half of the 1990s brought about (or at least made possible) better economic fundamentals in my country than in other transition economies. It 
was, however, undermined by the premature introduction of full convertibility of the Czech crown and by the resulting (or perhaps parallel, but independent) large inflow of foreign capital into the country. This coincidence of events led, of course, to the excessive growth of the money supply.

Our central bank tried not to be passive and started to interfere with the money supply, which was an expected error. The combination of two different rules (or regimes) whether in a transparent or nontransparent way-pegged exchange rate and monetary targeting-had very unpleasant consequences.

To return to our topic, we can say that the policy of pegged exchange rates was transparent, but in the world of global massive movements of capital it contained inherent risks. When investors lose trust in the currency and start speculative attacks against it, the pegging must be abandoned, which is not costless. The transition from one type of monetary rule to another is connected with instability, which is especially true for a small, open, transition economy with weak and shallow markets.

Our country finally moved to inflation targeting which is, in a favorable interpretation, a more complex policy regime than a simple monetary targeting or pegged exchange rate regime. In another interpretation, it is a resignation on accountable policy. It requires using the whole mix of central bank instruments, but no one knows in advance which of them will be used. In this respect, inflation targeting is not transparent and our experience forces me to argue that its results (at least its short-term results) are very dubious.

The Czech experience demonstrates that pegged exchange rate policy is suitable before deregulation of capital flows, whereas, after it, floating is inevitable. It shows as well the problems of inflation targeting in a transition economy. Our central bank did not have sufficient experience with monetary policy and, in addition, chose an extremely low inflation target which slowed down the economy too much. After that we could not get out of deflation.

Inflation targeting can have meaning only on condition of hitting the inflation target, which in our case was not done. The missing of the target was enormous; instead of 6 percent inflation we got deflation. Somebody could argue that it was a mistake, but I am not so sure.

To conclude, transparency has a meaning and plays a positive role only when all other preconditions of monetary policy are in place.

\section{Transparency in the Practice of Monetary Policy}

\section{J. Alfred Broaddus Jr.}

This has been a very useful conference in my view, and I am honored by this opportunity to be a part of it. As some of you may know, I was the second choice for this slot, but that doesn't bother me at all because the first choice was Don Brash, the Governor of the Reserve Bank of New Zealand and a pathbreaker in bringing both transparency and accountability to central banking in practice. I won't be able to fill Don's shoes completely, but I have a strong interest in this topic, and I am very happy that Bill and Dan saw fit to give me the opportunity to

J. Alfred Broaddus Jr. is the president of the Federal Reserve Bank of Richmond. The author thanks his colleague Marvin Goodfriend for assistance in preparing these remarks. The views expressed here are the author's and not necessarily those of the Federal Reserve Bank of Richmond or the Federal Reserve System. share some thoughts with this distinguished group.

Actually, it is hard to imagine that anyone interested in improving the conduct of monetary policy would not be interested in this topic. There is a growing consensus among monetary economists at this point that the impact of monetary policy on expenditure is transmitted primarily through the effects of policy actions on expectations regarding the future path of short-term interest rates rather than the current level of the overnight rate (see Woodford, 2001, p.17). Further, the more financial markets know about the reasons for a central bank's current policy actions and its longer-run policy intentions, the more likely it is that market reactions to policy actions will reinforce these actions and increase the effectiveness of stabilization policy. It follows that central banks should be highly transparent regarding both their long-term policy objectives and the shorter-term tactical actions they take with policy instruments.

Against this background, it seems to me that the Fed, along with other central banks, has made considerable progress in increasing transparency 
in recent years. When I first joined the Fed back in 1970 , to the extent that anyone thought explicitly about transparency issues at all, the idea seemed to be that limited transparency - or even no transparency - was best. Central banks in industrial democracies were thought to work most effectively behind the scenes, away from the glare of public scrutiny, at least in part because they could then quietly take appropriate actions that might be politically unpopular or, more broadly, difficult to explain to a public not well versed in the intricacies of finance (see Goodfriend, 1986). There was also a belief in some quarters that central banks could enhance the effects of certain policy actionsmost notably foreign exchange market intervention operations - if they kept market participants uncertain about their intentions.

Attitudes toward transparency appeared to change in the 1980s, partly reflecting progress made by economists in understanding the monetary policy transmission mechanism, and probably partly because of public demand, particularly in the United States, for greater openness in government and public policy in general. (As you may recall, the most widely read popular book about the Fed and Fed policy in the 1980s was somewhat derisively titled Secrets of the Temple.) Further, in the early 1980s Chairman Volcker publicly took responsibility for reducing inflation from its then high level, and subsequently took strong and temporarily painful actions to accomplish the reduction. Some public explanation of the need for these steps was required, and this need probably facilitated the transition to viewing transparency in a more favorable light. In any case, given the normal resistance to change in bureaucratic organizations, I believe the Fed has made remarkable progress over the last decade or so in opening up its conduct of monetary policy to market and public scrutiny.

Since the Fed is now quite open regarding many important aspects of its policy strategy and operations, and in view of the strong performance of the U.S. economy in recent years, at least up until the last several quarters, one might reasonably ask whether still greater transparency is necessary or even desirable in U.S. monetary policy. I think it is, and I will try to make this case in the next few minutes. Let me comment briefly on four points: (i) the transparency of our long-term inflation objective, (ii) what I'm going to refer to as the "intermediateterm transparency problem," (iii) the transparency of our policy directive including its "tilt," and (iv) the role of testimony, speeches, and other public statements by Fed officials in providing transparency.

\section{TRANSPARENCY OF THE LONG-TERM INFLATION OBJECTIVE}

Probably the most important thing about Fed monetary policy that the public wishes to know and needs to know with some precision is our longterm objective for inflation. Longer-term inflation expectations are obviously critical to households and businesses in committing to long-term investments, home purchases, insurance contracts, and wage and benefit agreements. Conversely, the Fed needs the public to understand and trust its longterm commitment to low inflation to achieve maximum benefit from this long-term strategy.

How to convey this objective credibly to the markets and the public has been a major focus of our policy research at the Richmond Fed for a long time. For many years I've personally been convinced that controlling inflation should be the Fed's overriding objective, that this objective should be explicit, and that it should be supported by a Congressional mandate. At one level, abstracting, for example, from political obstacles, this seems obvious. We know that the Fed has the ability to determine the long-run inflation rate with monetary policy, and theoretical analysis and all of our practical experience suggests we should use that power in the public interest to maintain low and stable inflation over time.

An explicit long-term inflation objective supported by a Congressional mandate would be a substantially beneficial step, in my view, even if it were limited to a verbal statement along the lines of the language in the proposed Neal Amendment to the Federal Reserve Act (see Black, 1990, and Greenspan, 1990). Quantifying the objective in terms of an explicit numerical rate (say, 2 percent per annum using the core personal consumption expenditures [PCE] inflation index) would make the objective even more transparent and probably more effective.

Committing to an explicit inflation objective would achieve at least three things. First, it would help anchor longer-term inflation expectations and therefore facilitate the longer-term transactions I noted earlier. Second, it would help prevent inflation scares in financial markets, which would allow the Fed to act more aggressively in response to downside risks in the economy with less concern that rising long-term interest rates might neutralize the effect of the action. 
Third, and most importantly, an explicit inflation objective would discipline the Fed to explain and justify short-run actions designed to stabilize output and employment against our commitment to protect the purchasing power of the currency over the long run. An explicit objective would force such explanations and justifications to be more sharply focused than in the current regime without such an objective. Routine, clear explanations of shortterm actions would build confidence in the Fed's commitment to price stability and over time help reinforce credibility for low inflation. If the explanations were made in testimony before Congress, supplemented perhaps by a written inflation report along the lines of the Bank of England model, Congress would be positioned to enforce an accountability for monetary policy that arguably is now weaker in the United States than in the United Kingdom and the European Monetary Union.

One final point here: The Fed's long-term commitment to price stability is now largely embodied in our current Chairman's demonstrated commitment to this objective, rather than being institutionally grounded in an explicit objective. It is therefore inherently tenuous, since its continuance will depend on the preferences of future chairmen and their susceptibility to political pressure to pursue other goals.

For all these reasons, it seems clear to me that the increased transparency that would be provided by an explicit long-term inflation objective would increase the probability that we will attain our goal over time. Some argue strongly for a dual objective that refers explicitly to output or employment as well as inflation. But both theory and experience indicate that the Fed cannot control real variables directly with monetary policy, and in my view there are reasonable grounds to presume that the Fed will optimize its contribution to the economy's overall performance by maintaining credibility for low inflation (see Goodfriend and King, 2001). A unitary goal focused on low inflation would strengthen credibility by making the Fed's commitment to this objective definite and unambiguous.

It is one thing to advocate an explicit inflation objective; it is another to actually put one in place. I doubt seriously that an explicit objective set and announced unilaterally by the Fed would be credible. Any explicit inflation objective would need to be accepted by the government as a whole through legislation or some other formal agreement, as such objectives are in countries that employ them. With its public standing high, the Fed seems well positioned currently to make the case for such a mandate.

\section{INTERMEDIATE-TERM ISSUES}

Even if the Fed obtains a price stability mandate, transparency issues are still likely to arise in practice-specifically, when current inflation or nearterm inflation projections deviate from the long-term objective. For example, inflation may rise above its objective at a time when real output is below potential and unemployment is rising. It would be difficult or impossible in this situation for the Fed to ignore the weakness in the real economy and act aggressively to bring inflation quickly back to target.

Some have argued that precisely this possibility makes an explicit inflation objective for the United States impractical. I don't find this objection particularly compelling. Especially if the Fed has previously established credibility, inflation may remain above its objective for some time without undue damage to the Fed's credibility if the Fed is transparent regarding its medium-term strategy for bringing inflation back to path. Even with established credibility, explaining this strategy clearly and convincingly to market participants and the general public would be challenging. Strategies and the accompanying explanations will have to be tailored to each case. In particular, the Fed may anticipate bringing inflation back to the objective more quickly in some cases than in others. Consequently, it may be useful for the Fed to announce intermediate-term inflation forecasts to assist the public in making financial and business decisions during the transition back to the long-term objective.

Beyond this, even if inflation is stable at or near its long-term objective, unanticipated shocks may push employment and output growth temporarily away from their sustainable noninflationary rates. Here, too, Fed transparency about its intentions will help the public gauge how production, employment, and interest rates will evolve in the medium term as the economy adjusts to the shock. Transparency is in the Fed's interest as well since it can help build confidence in the following: that, first, monetary policy can be effective in dealing with temporary departures of real activity from its long-term potential and, second, that the Fed has the competence to exploit this capability. More generally, I believe that the Fed's expertise regarding the functioning of the U.S. economy - while far from perfect-is now of high enough quality that transparency of our thinking about the economy's medium-term 
prospects can build public confidence and trust in periods of economic stress. To be sure, actual developments may deviate from our announced expectations in particular situations, but trust can be maintained if the Fed provides reasonable explanations for the deviations.

\section{TRANSPARENCY OF THE FEDERAL FUNDS RATE TARGET AND THE DIRECTIVE "TILT"}

Having dealt with longer-term and intermediateterm issues, let me now make a few comments about transparency as it relates to short-term policy tactics: specifically, transparency regarding the current federal funds rate target, the "tilt" of the directive language, and the statement released to the press after each Federal Open Market Committee (FOMC) meeting. It is in this area that the greatest progress has been made in increasing transparency over the last decade. Since February 1994, the funds rate target set at a particular FOMC meeting (previously released only after the next FOMC meeting) has been announced shortly after adjournment of the meeting where it is set. So markets now know the current target. And the Committee has released the tilt (or absence of a tilt) in the directive language along with the current funds rate target since its meeting on May 18, 1999. Previously, it too had been released only after the next FOMC meeting. ${ }^{1}$

This increased instrument transparency, in my view, is all to the good. I believe the immediate release of the tilt language is especially useful. Again, the effect of monetary policy is transmitted to the economy not only through the current level of the funds rate target but also through market expectations about the future level of the target, which are reflected in the short-term yield curve. Market participants are going to form these expectations in any event. By announcing the tilt immediately, the FOMC shares its best current estimate of emerging economic conditions that might affect the direction of any near- or intermediate-term change in the funds rate target, which should increase the efficiency with which markets form their expectations, help prepare markets and the public for changes in the target, and reduce short-term disruptions caused by leaks. In particular, since markets know the current tilt, they are better positioned to interpret the likely policy implications of incoming current economic data. For example, the release of strong data after disclosure of an upside tilt in the directive language should increase the probability that longterm rates will be bid upward in response. Consequently, immediate disclosure of the tilt should enable long-term interest rate adjustments to perform their stabilizing role in the economy more effectively.

While, again, considerable progress has been made in increasing the transparency of the Fed's short-term instrument settings, and its short-term expectations regarding at least the direction of future settings, in my view there is room for further progress. In particular, there may be different views about the extent to which a tilt in the directive in one direction or the other commits or obliges the Fed to a future funds rate change. To the degree that markets interpret a tilt as committing the Fed to future action, failure to take action may surprise or "whipsaw" markets. It should be possible for the Fed to mitigate this problem by emphasizing publicly that a tilt only implies a greater likelihood that any near- or intermediate-term change in the funds rate will be in a particular direction, and is not a commitment to any action. It might seem tempting to consider eliminating the tilt in the formulation of short-term policy to remove any confusion it may produce. But such a reduction in transparency would deprive the FOMC of the benefits of announcing the tilt noted above. Moreover, beyond these benefits, abandoning it would deprive the Committee of a useful way to keep in touch with the strength of its internal consensus regarding policy at any point in time and a valuable supplementary tool for reaching agreement on a funds rate target when there is a significant divergence of views regarding the appropriate level of the target.

Finally, it is important to recognize that the language of the press statement announcing the funds rate target and any tilt after each meeting also influences market expectations regarding future policy actions. This language is widely reported and interpreted currently in media coverage of FOMC meetings. In essence, the language in the statement,

\footnotetext{
1 Initially, the FOMC tilt statement referred to the likelihood of a future increase or decrease in the targeted federal funds rate. In January 2000 , the Committee announced that it had adopted new language for this portion of the statement. The new language describes the FOMC's assessment of the "balance of risks" with regard to heightened inflationary pressures or economic weakness in the foreseeable future, without reference to future policy actions. The objective of the change was to avoid potential confusion regarding the implications of the tilt announcement for future policy. In practice, however, financial market participants continue to draw inferences from the announcement regarding the likelihood of possible future policy actions.
} 
like the tilt language in the directive, is viewed by market participants as an additional short-term policy instrument.

\section{TESTIMONY AND SPEECHES}

The role of the Fed's explicit policy announcements in shaping market expectations of future policy actions is obviously important, but as anyone even slightly interested in Fed policy is well aware, public statements by individual FOMC members (including Reserve Bank presidents who are not currently voting Committee members) are at times especially important. This is particularly so in today's environment where media coverage of these utterances by cable television financial news channels, instant e-mail transmission of market analysis, and the like is much more extensive than even just a few years ago. Obviously, the Fed Chairman's remarks in congressional testimony (including answers to questions as well as prepared testimony), his speeches, and his interviews are followed more intensely than the comments of other FOMC participants, since the Chairman is clearly the most influential Committee member and only he speaks for the Committee as a whole. At times, however, comments of other participants can affect market expectations, at least in the short run: for example, if a comment is the Fed's first public reaction to a new economic report (particularly if the content of the report was unanticipated by markets) or if the comment comes at a time when markets are especially uncertain about near-term policy prospects. Consequently, we also receive our share of media attention. Bill Poole and I and, I expect, all of our colleagues at other Reserve Banks can tell stories about being covered by several reporters even when making speeches in fairly remote parts of our respective Districts.

Some argue that this form of Fed transparency may be counterproductive, at least at times, if the views expressed in these comments seem inconsistent-particularly if they appear to conflict with a recent FOMC decision or a public statement by the Chairman. On occasion I have personally received criticism and complaints from market professionals and others when they have found my statements at variance with other Fed statements or confusing in some other way, and I will acknowledge that on a few occasions my remarks may have briefly complicated the formation of market expectations.

Over time, however, speeches and other public statements by individual FOMC participants provide markets and the public with a more robust and complete understanding of thinking inside the Fed about current economic and financial conditions and near-term prospects than that provided solely by the policy announcements I just discussed. Also, it is important to recognize that market analysts are adept at filtering and appropriately weighting press reports of individual FOMC participant remarks in the context of the broad range of Fed public statements from all sources. In short, I believe a convincing case can be made that the public remarks of individual Reserve Bank presidents and other FOMC participants increase the efficiency with which markets form short-term policy expectations.

I would offer one other-admittedly speculative-note on this point. It is obvious, again, that the Fed Chairman speaks with by far the most influential voice among FOMC participants. It might appear superficially that comments by other participants that seem to be "off message" might create confusion about the Fed's intentions and undermine the force of the Chairman's statements. As I just suggested, there might be a little of this from time to time, but I doubt these instances are of much significance. Again, markets are well aware of the much greater weight of the Chairman's statements and discount the remarks of other FOMC participants accordingly. Perhaps more importantly, public commentary by other participants reinforces the Chairman's credibility in the eyes of informed observers of Fed policy, since they demonstrate that the Chairman leads, builds consensus among, and speaks for a thoughtful, competent group of policy professionals who naturally have diverse views on specific policy choices. If the public believed the Chairman was conducting policy unilaterally, he or she would be more vulnerable to an abrupt loss of public confidence. This might not be a risk for the current Chairman, who justifiably enjoys exceptionally high public respect, but it could be a problem for a future Chairman.

\section{CONCLUSION}

Again, I have enjoyed participating in this panel discussion. This conference has addressed what is clearly a crucial topic in understanding how monetary policy affects the economy and how it might be improved. The subject deserves continued research. Thanks to this conference, I am confident it will get it. 


\section{REFERENCES}

Black, Robert. “In Support of Price Stability.” Federal Reserve Bank of Richmond Economic Review, January/February 1990, pp. 3-6. (Statement before the Subcommittee on Domestic Monetary Policy of the U.S. House of Representatives Committee on Banking, Finance, and Urban Affairs.)

Goodfriend, Marvin. "Monetary Mystique: Secrecy and Central Banking." Journal of Monetary Economics, January 1986, 17(1), pp. 63-92.

and King, Robert. "The Case for Price Stability," in European Central Bank, First ECB Central Banking Conference, Why Price Stability? 2001, pp. 53-94.

Greenspan, Alan. Statement before the U.S. Congress, House of Representatives, Subcommittee on Banking, Finance, and Urban Affairs hearing. Zero Inflation. 101th Congress, Session 1. Washington, DC: Government Printing Office, 1990.

Woodford, Michael. "Monetary Policy in the Information Economy." Delivered at the Federal Reserve Bank of Kansas City symposium Economic Policy for the Information Economy, Jackson Hole, Wyoming, August 2001. 